\title{
SERVIÇO DE NEUROLOGIA DA FACULDADE DE MEDICINA DA UNIVERSIDADE DE S. PAULO
}

Desde 1941 vem sendo realizadas, neste Serviço, sob a direção do Prof. Adherbal Tolosa, reuniões mensais de estudo nas quais são relatados e discutidos os casos clínicos e anatomo-clínicos mais interessantes. Essas reuniões são assistidas por outros especialistas, convidados quando o assunto a discutir os interessa particularmente ou quando sejam necessários seus esclarecimentos. Constituem, essas reuniões, excelente demonstração da atividade do Serviço de Neurologia da Faculdade de Medicina de S. Paulo. Damos a seguir o sunário dos casos discutidos nas reuniões dos primeiros mezes do ano corrente.

\section{Reunião realizada em 2 de Fevereiro}

Obserzações clinicas:

1) Caso O. C. (6.699) Encefalopatia infantil, oligofrenia, espinha bifida $e$ outras malformą̧ões congenitas. Dr. O. F. Julião.

2) Caso A. P. (7.283) Tabo-paralisia. Dr. J. A. Caetano da Silva Jor.

3) Caso J. F. (7.386) Atrofia ótica luética. Dr. J. M. Taques Bittencourt.

4) Caso K. K. (7.408) Paralisia geral com agitação psico-motora. Dr. J. M. Taques Bittencourt.

5) Caso J. T. (7.347) Hemianopsia por traumatismo occipital antigo. Dr. J. A. Caetano da Silva Jor. de Assis.

6) Caso J. P. (7.468) Hemiplegia. lues, arterio-esclerose. Dr. J. Lamartine

7) Caso F. O. M. (7.417) Hemiplegia por arterite luética. Dr. A. Conde. 


\section{Observações anátomo-clínicas on neuro-cirúrgicas:}

1) Caso M. L. (7.382) Tumor intra-medular. Tratava-se de um paciente que foi internado por ter ficado bruscamente paraplégico após raquianestesia praticada para uma operação de hernia inguinal: o doente faleceu dias depois. $\mathrm{O}$ estudo anátomo-clínico demonstrou que a paraplegia, atribuida a principio à raquianestesia, era, na realidade, consequencia de um volumoso tumor intra-medular, localizado na região cervical. O interesse principal do caso residia na ausencia de qualquer sintomatologia neurológica até o momento em que foi praticada a raquianestesia. O tumor, muito volumoso, deformava inteiramente a medula, deslocando a substância cinzenta e branca para a periferia. () caso será publicado após a terminação do estudo histo-patológico. Drs. J M. Taques Bittencourt e W. Maffei.

2) Caso W. B. (6.902) Tumor intracraniano cuja localização não poude ser determinada pelos recursos neurológicos habituais e por falta de cooperação do doente, em virtıde do seu precario estado geral. $O$ exame anatomo-patológico mostrou tratar-se de um tumor do $3 .^{\circ}$ ventriculo, provavelmente um ependinoma. Drs. V. Venturi e W. Maffei.

3) Caso C. N. G. (7.501) Falsa garra cubital dupla produzida por ferimentos locais nas mãos. $O$ paciente, de nacionalidade paraguaia, fora atingido em varias partes do corpo, durante a guerra do Chaco, por estilhasos de granada. Um deles alojado no cranio produziu osteomelite frontal e secundariamente, crises epileptiformes, o que exigiu intervenção cirúrgica, 1! aticada, aqui em S. Paulo, pelo Dr. Carlos Gama. Outros fragmentos lesaram, em ambas as mãos, a região palmar, determinando, secundariamente, retrações aponevróticas e fibro-tendinósas que produziram garra cubital bi-lateral. Foram discutidos o diagnóstico diferencial, a patogenia e as possibilidades da terapeutica cirúrgica para melhorar as condiçōes das mãos do paciente. Dr. R. Tenuto.

\section{Reunião realizada em 2 de Março}

\section{Observações clinicas:}

1) Caso V. G. (7.519) Espinha bifida oculta e perturbações da miç̧ão. Dr. O. F. Julião.

2) Caso M. F. (7.585) Síndromo epilético. Dr. J. A. Caetano da Silva Jor.

3) Caso C. F. (7.588) Psicastenia e lues. Dr. C. V. Savoy.

4) Caso S. A. (7.103) Encéfalo-mielite de natureza indeterminada instalada bruscamente. Os varios exames subsidiarios não esclareceram a etiologia do processo. Como o estado permanecesse estacionario durante os dois mezes de internação foi o paciente removido para o Asilo de Invalidos onde continuará sob observação. Dr. J. Lamartine de Assis.

5) Caso A. M. (7.587) Tumor intra-craniano, provavelmente localizado no terceiro ventriculo, de acordo com os dados neurológicos e ventriculográficos. Em virtude do agravamento do síndromo hipertensivo intracraniano, foi praticada craniotomia descompressiva. Como terapeutica, foi iniciada a radioterapia profunda. Nítidas melhoras permitiram ao doente pedir alta e continuar a medicação em ambulatorio. Dr. J. M. Taques Bittencourt.

6) Caso N. M. (6.157) Aracnoidite espinhal que produziu um sindromo paraplégico de evolução ascendente, originando em certo periodo da evolução da moléstia uma tetraplegia compléta. Operado, fez-se o debridamento das aderencias meningéas e, em seguida, a radioterapia. O interesse maior do caso reside 
112 evolução, que só se tornou satisfatória após um ano de radioterapia. $\mathrm{O}$ doente saiu da enfermaria quasi completamente bom, locomovendo-se com auxilio de bengala. Dr. J. M. Taques Bittencourt.

\author{
Reunião de 6 de Abril
}

Obseri'ações clínicas:

1) Caso F. G. (7.435) Tabo-paralisia medicada pela malaria. Dr. J. Lamartine de Assis.

2) Caso G. P. (7.192) Sindromo hipertensivo intracraniano produsido, possivelmente, por cisticercose encefálica. O estudo ventriculográfico mostrou bloqueio do aqueduto de Sylvius. Foi feita a craniotomia descompressiva. O exame do liquido céfalo-raquidiano foi o unico dado para o diagnóstico de cisticercose. Dra. M. E. Bierrembach Khoury.

3) Caso J. R. (7.702) Sindromo epiléptico em doente portador de afecção cardiaca (molestia mitral), com aura olfativa e psíquica do tipo dos "uncinated fits" de Jackson (dreamy state). O caso será publicado posteriormente. Dr. R. Melaragno.

4) Caso A. S. (7.684) Diabéte $e$ neuropatia. Num antigo diabético de dificil controle pela insulina, instalou-se uma neurite do ciático poplitêo externo no lado esquerdo e mioclonias no pé esquerdo e na mão direita. Foi discutida a patogenia dos disturbios mioclônicos. O caso será publicado. Dr. J. M. Taques Bittencourt.

5) Caso A. C. (6.655) Caso complexo no qual não foi possivel diagnóstico preciso. Trata-se de um ex-jogador de futebol cuja moléstia se iniciou com um síndromo de Weber, instalado paulatinamente, acometendo o motor ocular comum à direita e hemiplegia esquerda. Posteriormente o olho esquerdo sofreu um processo de atrofia global com infecção secundária, sendo enucleado. Internado na enfermaria, apresentava um estado psíquico especial com euforia e mória, levando ao diagnóstico de tumor frontal. No entanto, o estudo ventriculográfico mostrou deformação dos pólos occipitais dos ventriculos. O sindromo de Weber dininuiu de intensidade, permanecendo as perturbações psíquicas. Foram discutidas varias hipóteses diagnósticas, nenhuma plenamente satisfatória. Dr. A. Lefèvre.

Obseri'açôes anátomo-clinicas e neuro-cirúrgicas:

1) Caso A. L. O. (7.496) Paraplegia espasmódica por compressão medular, com discordancia entre os sinais clínicos e a mielografia. Os disturbios sensitivos localizavam a lesão em D3 ao passo que a iodipina, injetada por via sub-occipital, parou na altura de C3. Foram praticadas duas intervenções: a primeira, ao nivel das primeiras vertebras dorsais, nada mostrando de anormal; a segunda, ao nivel de $\mathrm{C} 3$ e $\mathrm{C} 4$, mostrou paquimeningite hemorragica e aracnoidite. Grandes melhoras após esta ultima intervenção. Drs. C. Ganı e J. Lamartine de Assis.

2) Caso J. R. (7.467) Amolecimento protuberancial por arterite e trombose da arteria basilar. Tratava-se de um doente que repentinamente teve um ictus, sendo internado em estado de coma, falecendo 24 horas depois. Fora feito 0 diagnóstico de hemorragia intra-encefálica pela gravidade da sintomatologia: coma, hipertermia, hipertonia precoce, sinal de Babinski bilateral e perturbações respiratorias. Drs. R. Tenuto e W. Maffei.

3) Caso E. S. M. (6.740) Medulo-ependimoma do $4 .^{\circ}$ aentriculo com cistos hemáticos na calota protuberancial. Caso observado durante longo tempo. $\mathrm{O}$ coente, ao ser internado, apresentava facies de Hutchinson, lesão dos nervos 
oculares e disturbios cerebelares que levaram ao diagnóstico de polioencefalite superior. Varios exames de liquor, fornecendo sempre liquido hemorrágico e xantocrômico, fizeram pensar em encefalite hemorrágica. $O$ aparecimento posterior de papila de estase e sinais de hipertensão intra-craniana levaram ao diagnóstico de neoplasia. As ventriculografias mostraram hidrocefalia interna com com1’ressão e desvio do aqueduto de Sylvius. Após o óbito, o exame anatômico mostrou tratar-se de meduloependimoma do assoalho do $4 .^{\circ}$ ventriculo com invasão da calota protuberancial, desvio do aqueduto de Sylvius e deformação do pedunculo cerebral. O caso será publicado. Drs. O. F. Julião, C. Gama e W. Maffei. 